PJOS 5(1), 2013

\title{
Constraints on the semantic extension of onomatopoeia
}

\author{
Kimi Akita ${ }^{1}$ \\ Studies in Language and Culture, Osaka University
}

\begin{abstract}
This article proposes three constraints on the complex polysemy patterns of onomatopoeia. Onomatopoeic forms for thirty types of sounds were collected from Japanese, Korean, Mandarin Chinese, and English, and examined in terms of their semantic extensibility and extension types. It was found that 1) Chinese onomatopoeia is generally resistant to semantic extension, 2) onomatopoeic forms for voice in Japanese and Korean are less likely to be polysemous than those for noise, many of which show metonymical extension, and 3) many onomatopoeic verbs in English have metaphorical meanings. These three patterns can be accounted for by generalizations that associate high semantic extensibility with referential specificity, event-structural complexity, and syntactic coreness, respectively. Each of these generalizations finds some independent support, and is compatible with or complementary to a frame-semantic approach to polysemous onomatopoeic forms, which has been taken to discuss existing, rather than non-existing, cases in each language. This study is, thus, an attempt to locate sound symbolism research in the center of cognitive studies of language.
\end{abstract}

\section{Introduction}

The last two decades have seen a revitalization of the study of sound symbolism and sound-symbolic words, notably in the fields of cognitive/functional linguistics (Kita, 1997; Ibarretxe-Antuñano, 2006; Dingemanse, 2011) and cognitive psychology (Maurer, Pathman, \& Mondloch, 2006; Imai, Kita, Nagumo, \& Okada, 2008; Nygaard, Cook, \& Namy, 2009). ${ }^{2}$ This article pays further attention to particular types of sound-symbolic words with respect to lexical polysemy, which has been one of the central issues in cognitive linguistics (Lakoff \& Johnson, 1980, 1999; Lakoff, 1987; among many others). Specifically, we propose three constraints on the meaning extension of onomatopoeic forms (henceforth OFs; i.e., sound-mimicking words), such as growl and crack, in four languages - Japanese, Korean, Mandarin Chinese, and English - whose OFs are welldocumented. It is argued that the semantic extensibility of OFs differs both within and across languages, and the patterns of their semantic extension are correlated with their referential specificity, event-semantic complexity, and syntactic status. These correlations clarify the role of frame semantics (Fillmore, 1982; Fillmore \& Baker, 2010) in a typological pursuit of OFs.

All of these languages have a large inventory of OFs, for which more than one dictionary have been published (see Section 3). However, as the following examples show, they are mainly realized as adverbs modifying verbs (or as verbal complements) in Japanese (Hamano, 1998), Korean (Sohn, 1994), and Chinese (Noguchi, 1995; Meng, 2012), but as verbs (and nouns) in English (Levin, 1993; see also Talmy, 1985). ${ }^{3}$

\footnotetext{
${ }^{1}$ Email: akitambo@lang.osaka-u.ac.jp

2 Throughout this article, we use "sound-symbolic words" as a cover term for what are called "ideophones" in African or general linguistics, "expressives" in South and Southeast Asian linguistics, and "mimetics" in Japanese linguistics. See Hinton, Nichols, \& Ohala (1994) and Voeltz \& Kilian-Hatz (2001) as two milestone volumes on this word class.

${ }^{3}$ The abbreviations used in this article are as follows: $\mathrm{ACC}=$ accusative; CONJ = conjunctive; $\mathrm{COP}=$ copula; $\mathrm{DAT}=$ dative $; \mathrm{DECL}=$ declarative $;$ DUR $=$ durative $;$ GEN = genitive; $\mathrm{NOM}=$ nominative $;$ NPST $=$ nonpast $; \mathrm{OF}=$
} 


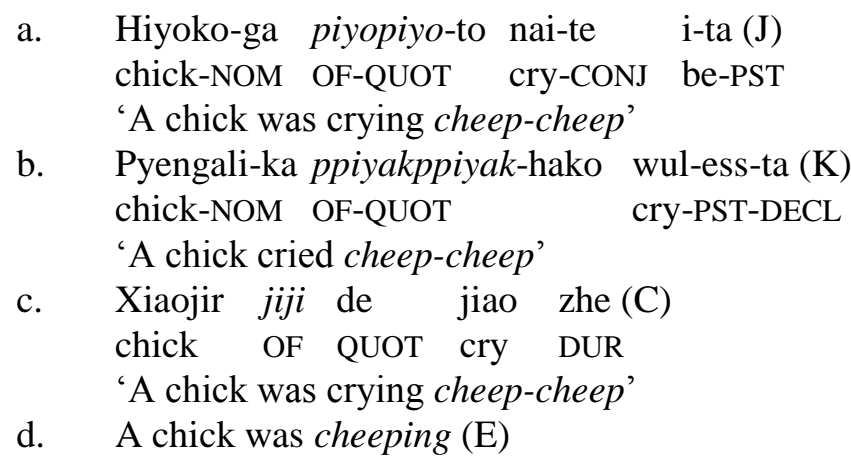

This basic syntactic difference between English and the three Asian languages plays a critical role in our crosslinguistic comparison of the semantic extensibility of OFs (Section 5.3).

The organization of this article is as follows. In Section 2, we summarize related (language-internal) studies on the polysemy of OFs and clarify the aim of the present one. Section 3 describes the methods of the present study. Section 4 reports the results for the semantic extensibility of OFs in the four languages and their extension types. In Section 5 , we propose three constraints that capture the results and support them with some independent evidence. Section 6 concludes the article.

\section{Previous studies}

Recent studies in cognitive semantics have revealed some important facts about the semantic extension of OFs in individual languages, notably Japanese. Each of these facts pertains to the generalizations to be made in the following sections. It should be noted that these previous descriptions are partial in that they are mostly language-internal and limited to attested examples. General constraints on semantic extension, such as the ones we discuss in this article, would need a crosslinguistic comparison of both attested and unattested examples.

Many instances of metaphorical and metonymical extensions have been reported for OFs in Japanese (Lu, 2006; Yu, 2012a, b; among others). For example, gikuri 'crack' in (2a) is metaphorically extended to have a non-auditory meaning in (2b). More specifically, this example can be analyzed as involving a cross-domain mapping from a physical impact to a psychological impact (see Lakoff \& Johnson, 1980).

$$
\begin{aligned}
& \text { Metaphorical extension (J): } \\
& \text { a. Kata-ga gikuri-to nat-ta } \\
& \text { shoulder-NOM OF-QUOT sound-PST } \\
& \text { '[My] shoulder went } \text { crack' } \\
& \text { b. Ai-wa gikuri-to odoroi-ta } \\
& \text { Ai-TOP OF-QUOT be.surprised-PST } \\
& \text { 'Ai was surprised with a start' }
\end{aligned}
$$

What is noteworthy about Japanese OFs is the prevalence of the "fictive" type of conceptualization (Talmy, 1996), which one may consider a special case of metonymy 
PJOS 5(1), 2013

(Yu, 2012a). As Mikami (2006) points out, many OFs in Japanese can refer to a state of an object that is associated with, but not accompanied by, the sound they imitate. Fictive metonymy is divided into two types. The first type is called vestigial cognition (Kunihiro, 1985). For example, the presumed original meaning of barabara is onomatopoeic (i.e., mimicking the pattering sound/manner of small hard objects being scattered), as illustrated in (3a). In (3b), however, this same word is used to describe the static configuration of many prefabricated houses, which are conceptualized as if they had been scattered from the sky before the time. Such a hypothetical causal relation is absent in (2) above. $^{4}$

(3) Vestigial metonymical extension (J):
a. Gake-no ue-kara koisi-ga barabara oti-te ki-ta cliff-GEN top-from pebble-NOM OF fall-CONJ come-PST 'Pebbles came pattered down from the top of the cliff' field-GEN inside-DAT build-sell-GEN prefab-residence-NOM barabara-to tat-te i-ru
b. Hatake-no naka-ni tate-uri-no purehabu-zyuutaku-ga OF-QUOT build-CONJ be-NPST 'Some ready-made prefabricated houses are scattered in the field'

(Mikami, 2006: 206)

The other type of fictive metonymical conceptualization is called prospective cognition (Nakamoto, Kotani, \& Isahara, 2004). For example, katikati, which is an OF mimicking a clinking noise in (4a), represents the solid state of frozen laundry that would make a clinking sound if one hit it in (4b). In this case, the OF mimics an expected sound.

$$
\begin{aligned}
& \text { Prospective metonymical extension (J): } \\
& \text { a. ... koori-ga katikati-to nar-u oto-ga suzusi-i } \\
& \text { ice-NOM OF-QUOT sound-NPST sound-NOM cool-NPST } \\
& \text { '... [I] find the clinking sound of ice cubes cool' } \\
& \text { b. ... sentakumono-ga katikati-ni koot-te-simat-ta } \\
& \text { laundry-NOM OF-COP freeze-CONJ-end.up-PST } \\
& \text { '... the laundry has frozen solid' }
\end{aligned}
$$

(Mikami, 2006: 211-212)

$\mathrm{Yu}(2012 \mathrm{a}, \mathrm{b})$ reconsiders these and other metonymical instances in terms of frame evocation. In this supplementary account, Japanese OFs, especially those for non-vocal sounds, are assumed to evoke highly specific background situations (or "frames") (see also Akita, 2012; see Fillmore \& Baker, 2010 for the latest introduction to frame semantics), and they make these metonymical extensions (i.e., extensions between frame elements) common. This issue will be further discussed with similar examples in other languages in Section 5.

Two more related observations, this time in other languages, are worth mentioning here. First, many English onomatopoeic verbs are known to have manner-of-speech meanings, as illustrated in (5b) (see also Inoue, 2010). In this type of metaphorical

\footnotetext{
${ }^{4}$ The present cases of fictive metonymy also involve metaphor (i.e., cross-domain mapping) in that they represent states by referring to sounds associated with them. See Section 3 for our definition of each type of semantic extension.
} 
extension, the image of a crying animal is mapped to that of a human speaker in a particular emotional state (e.g., ANGER).

$$
\begin{aligned}
& \text { a. A wolf howled in the woods } \\
& \text { b. The neighbors howled "Futz" }
\end{aligned}
$$

(Zwicky, 1971: 226; emphasis added)

Second, Takeda (2001) discusses the low referential specificity of Chinese OFs. For example, dida can be used for a horse's clip-clop, a human's tramp, drops of water, the ticktock of a clock, a heartthrob, and blinks. This is quite contrastive to Japanese, which requires distinct OFs for all these sounds (i.e., pakapaka 'clip-clop', dosidosi 'tramping', potapota 'dripping', tikutaku 'ticktock', dokidoki 'the heart throbbing', and patipati 'blinking'). In Section 5, it will be shown that English is another language that is abundant in such referentially underspecified OFs. Kageyama (2013) makes a similar observation for Hungarian onomatopoeic verbs (e.g., dörög for a roll of thunder, a roar of anger, a roar of guns, etc.). All these cases are not considered polysemous, as they involve no unidirectional mapping between particular types of sound emitters. In fact, $\mathrm{Yu}$ (2012b) points out the rarity of polysemous OFs in Chinese (cf. Lu, 2006).

In summary, previous studies in the cognitive semantics of OFs have achieved some important, if partial, findings. What is crucially lacking in them is a general discussion across languages. As we see below, some of the above semantic properties of OFs are more or less shared across languages, while others are not. Moreover, the previous findings are all concerned with what type of semantic extension is observed. It has not yet been made clear what type of semantic extension is not present or preferred. The purpose of the present study is to present a basic description of the semantic extensibility of OFs in the four languages, and to uncover a set of constraints behind the extension patterns both within and across languages.

\section{Methods}

As the first step toward the semantic typology of OFs, we examined the semantic extensibility of OFs for thirty types of sounds in the four languages. The sound list (see (6)) consisted of fifteen types of voices (i.e., vocal, animate sounds) and fifteen types of noises (i.e., non-vocal, inanimate sounds), both randomly chosen. The animacy of sound emitters was considered because Japanese linguistics traditionally distinguishes voice OFs ("giseigo") and noise OFs ("giongo"), and the two types of OFs appear to behave differently in semantic extension (see Section 5.2; cf. Nuckolls, 2010; Yu, 2012a). Eight of the fifteen vocal sounds were human voices, and the remaining seven were animal voices.

(6) a. Voices:

i. Human:

1) humming of a crowd, 2) shrill laughter, 3) whispering, 4) vomiting, 5) muttering, 6) screaming, 7) grumbling, 8) chattering

ii. Non-human:

9) barking of a dog, 10) neighing of a horse, 11) cawing of a crow, 12) meowing of a cat, 13) chirping of sparrows, 14) squeaking of a mouse, 15) quacking of a duck 
PJOS 5(1), 2013

b. Noises:

16) the sound of ripping a thin wooden board, 17) the sound of heavy rocks dropping into water, 18) the sound of keys dangling, 19) the sound of a saw, 20) the sound of water drops dripping on a hard surface, 21) the sound of cutting vegetables roughly, 22) noisy footsteps, 23) the sound of boiling water, 24) the sound of small drums, 25) the sound of small stones dropping into water, 26) the sound of water moving in a swaying bottle, 27) the sound of scratching the rice scorched and stuck to a frying pan, 28) the sound of many coins, 29) the sound of glass being broken, 30) the sound of thunder

The relevant OFs were first collected from dictionaries of OFs or sound-symbolic words in general in each language (Japanese: Kakehi, Tamori, \& Schourup, 1996; Korean: Aoyama, 1991; Mandarin Chinese: Noguchi, 1995; English: Kloe, 1977), and then checked verbally (i.e., referring to relevant sound emitters and situations) with one or two native speakers of the language. We did not find appropriate OFs for two vocal sounds (i.e., the humming sound of a crowd (\#1) and a grumbling voice (\#7)) in Chinese. Moreover, this language did not allow us to use distinct forms for three pairs of sounds: jijizhazha for chattering (\#8) and chirping of sparrows (\#13), cila(cila) for the sound of ripping a thin wooden board (\#16) and the sound of a saw (\#19), and pa(papapa) for the sound of keys dangling (\#18) and noisy footsteps (\#22). (Actual word lists are presented in the next section.)

Each of the 118 OFs was examined for semantic extensibility and, if it was found to be polysemous, extension type. We employed arguably the most common definitions for the latter (Lakoff \& Johnson, 1980, 1999; Lakoff, 1987; Croft, 1993). Metaphor is a domain-to-domain mapping (e.g., scream 'write sensationally'). Metonymy is a withindomain extension (e.g., zakuzaku: the sound of many coins $\rightarrow$ a large sum of money). The two fictive types of semantic extension involve rather rich domains that contain inferred events in the past or future (see Section 2 for specific examples). As summarized in Figure 1, as far as OFs are concerned, all fictive expressions are metonymical, and all metonymical expressions involve metaphorical mappings between auditory and nonauditory domains. Therefore, we call the factive type of metonymy "factive metonymy" and the non-metonymical type of metaphor "only metaphor." Note that domains correspond to "frames" in frame semantics.

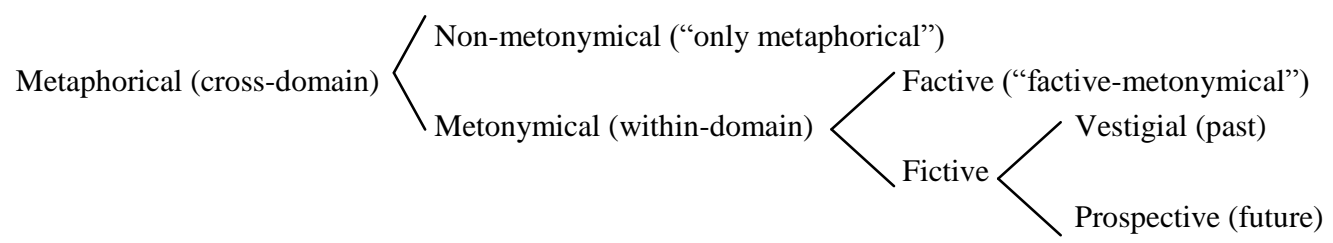

Figure 1. Types of semantic extension in OFs

For the sake of confirmation, all of the data was examined by the author and another cognitive linguist. The inter-examiner concordance rate for monosemous vs. polysemous judgments was $100 \%(118 / 118)$. 


\section{Results}

Despite the limited scope of the present study, it was revealed that the semantic extensibility of OFs depends at least on the language and the semantic type to which they belong. The results are presented in Tables 1 (details) and 2 (summary). In Table 1, OFs with multiple meanings are followed by a check $(\checkmark)$, and those without are followed by an asterisk.

Table 1. Semantic extensibility of OFs in the four languages

\begin{tabular}{|c|c|c|c|c|c|c|c|c|c|}
\hline & & Japanese & & Korean & & Chinese & & English & \\
\hline Voice & 1 & doyadoya & $*$ & swullengswulleng & $*$ & $\mathrm{n} / \mathrm{a}$ & & hum & $\checkmark$ \\
\hline \multirow[t]{7}{*}{ (+human) } & 2 & kerakera & $*$ & kkelkkel & $*$ & haha & $*$ & cackle & $\checkmark$ \\
\hline & 3 & hisohiso & $*$ & ssoktokssoktok & $*$ & xisuo & $\checkmark$ & whisper & $\checkmark$ \\
\hline & 4 & gebogebo & $*$ & uweyk & $*$ & wala & $*$ & barf & $\checkmark$ \\
\hline & 5 & gonyogonyo & $*$ & wumwulwumwul & $\checkmark$ & jiligulu & $*$ & mutter & $\checkmark$ \\
\hline & 6 & gyaagyaa & $*$ & kolaykolay & $*$ & $a a a$ & $*$ & scream & $\checkmark$ \\
\hline & 7 & buriburi & $\checkmark$ & wakuwaku & $\checkmark$ & $\mathrm{n} / \mathrm{a}$ & & grumble & $\checkmark$ \\
\hline & 8 & petyapetya & $*$ & caycalcaycal & $*$ & jijizhazha & $*$ & chatter & $\checkmark$ \\
\hline \multirow[t]{7}{*}{ (-human) } & 9 & wanwan & $*$ & mengmeng & $*$ & wangwang & $*$ & bowwow & $*$ \\
\hline & 10 & hinhin & $*$ & hihing & $*$ & huierhuier & $*$ & neigh & $*$ \\
\hline & 11 & kaakaa & $*$ & kkakkkak & $*$ & yaya & $*$ & caw & $*$ \\
\hline & 12 & nyaanyaa & $*$ & yaongyaong & $*$ & miao & $*$ & meow & $*$ \\
\hline & 13 & tyuntyun & $*$ & ccaykccayk & $*$ & jijizhazha & $*$ & chirp & $\checkmark$ \\
\hline & 14 & tyuиtуuи & $*$ & ccikccik & $*$ & $j i j i$ & $*$ & squeak & $\checkmark$ \\
\hline & 15 & gaagaa & $*$ & $k k w a y k k k w a y k$ & $*$ & gaga & $*$ & quack & $\checkmark$ \\
\hline \multirow[t]{15}{*}{ Noise } & 16 & beriberi & $*$ & ccwakccwak & $\checkmark$ & cila & $*$ & rip & $\checkmark$ \\
\hline & 17 & dobodobo & $*$ & chempengchempeng & $*$ & putong & $*$ & gurgle & $\checkmark$ \\
\hline & 18 & gatyagatya & $*$ & talkataktalkatak & $*$ & $p a$ & $*$ & clatter & $\checkmark$ \\
\hline & 19 & kikokiko & $*$ & ssukssakssukssak & $*$ & cilacila & $*$ & rasp & $\checkmark$ \\
\hline & 20 & potapota & $*$ & ttokttok & $\checkmark$ & dida & $*$ & trickle & $\checkmark$ \\
\hline & 21 & tyarityari & $*$ & cayngkulangcayngkulang & $*$ & dingdang & $*$ & jingle & $\checkmark$ \\
\hline & 22 & dokadoka & $\checkmark$ & kwangkwang & $*$ & papapapa & $*$ & tramp & $\checkmark$ \\
\hline & 23 & bokoboko & $\checkmark$ & pwukulpwukul & $\checkmark$ & gugu & $*$ & burble & $\checkmark$ \\
\hline & 24 & zyakazyaka & $\checkmark$ & khwungkhwung & $*$ & dongdong & $*$ & blare & $\checkmark$ \\
\hline & 25 & potyapotya & $\checkmark$ & calpatang & $*$ & pia & $*$ & splash & $\checkmark$ \\
\hline & 26 & taputapu & $\checkmark$ & chollong & $\sqrt{ }$ & gudonggudong & $*$ & plop & $*$ \\
\hline & 27 & karikari & $\checkmark$ & atutukatutuk & $\checkmark$ & kuchikuchi & $\checkmark$ & crisp & $\checkmark$ \\
\hline & 28 & zakuzaku & $\checkmark$ & songsong & $\checkmark$ & $c a$ & $*$ & crunch & $\checkmark$ \\
\hline & 29 & baribari & $\checkmark$ & ccyangkulang & * & piaca & $*$ & crack & $\checkmark$ \\
\hline & 30 & gorogoro & $\checkmark$ & twululu & $\checkmark$ & gulugulu & $*$ & growl & $\checkmark$ \\
\hline
\end{tabular}

Table 2. Polysemous OFs in the four languages

\begin{tabular}{c|ccc}
\hline & Voice & Noise & Total \\
\hline Japanese & $1 / 15(6.67 \%)$ & $9 / 15(60.00 \%)$ & $10 / 30(33.33 \%)$ \\
Korean & $2 / 15(13.33 \%)$ & $7 / 15(46.67 \%)$ & $9 / 30(30.00 \%)$ \\
Chinese & $1 / 13(7.69 \%)$ & $1 / 15(6.67 \%)$ & $2 / 28(7.14 \%)$ \\
English & $11 / 15(73.33 \%)$ & $14 / 15(93.33 \%)$ & $25 / 30(83.33 \%)$ \\
\hline Total & $15 / 58(25.86 \%)$ & $31 / 60(51.67 \%)$ & $46 / 118(38.98 \%)$ \\
\hline
\end{tabular}

First, in accord with $\mathrm{Yu}$ (2012b), Chinese OFs were found to be generally resistant to semantic extension (the rate of polysemous items: $7.14 \%$ ) compared to OFs in the other three languages $(48.89 \%)$ (Fisher's exact test: $p<.001)$. The OFs for the sound of cutting vegetables roughly in (7) illustrates this clearly. Hereafter, (i)-examples illustrate basic, onomatopoeic meanings, whereas (ii)-examples illustrate extended meanings. 
PJOS 5(1), 2013

(7) OFs for the sound of cutting vegetables roughly:

a. Japanese:

i. Ai-ga retasu-o zakuzaku kit-ta 'Ai cut the lettuce crunch-crunch'

ii. Ai-ga mahuraa-o zakuzaku an-da 'Ai knitted a scarf coarsely' (only metaphorical)

b. Korean:

i. Suming-i pha-lul songsong ssel-ess-ta

'Suming sliced leeks crunch-crunch'

ii. Kwumeng-i songsong na-ess-ta

'Many large holes have been made' (vestigial)

c. Chinese:

i. Jing $\underline{\text { ca de }}$ yi sheng ba cai qie xia

'Jing cut the vegetable with a crunch'

ii. $\phi$

d. English:

i. Patty crunched potato chips

ii. The computer crunched the data (only metaphorical)

Second, the Japanese and Korean (and Chinese) results suggest the rarity of polysemy in voice OFs (the rate of polysemous items: $10.00 \%$ ), compared to noise OFs (56.67\%) (Fisher's exact test: $p<.001$ ). For example, the OFs for a mouse's cry in the three languages in (8) do not have additional meanings. (We excluded the babytalk uses of the OFs, which do metonymically describe a mouse (cf. Yu, 2012a).) However, the Japanese and Korean OFs for the sound of cutting vegetables in (7) and those for boiling water in (9) do have extended, non-auditory meanings.

(8) OFs for a mouse's cry:

a. Japanese:

i. Nezumi-ga tyuutyuu nai-ta 'A mouse cried squeak-squeak'

ii. $\phi$

b. Korean:

i. Cwi-ka ccikccik-hako ul-ess-ta 'A mouse cried squeak-squeak'

ii. $\phi$

c. Chinese:

i. Laoshu jiji de jiao zhe 'A mouse was crying squeak-squeak'

ii. $\phi$

d. English:

i. A mouse is squeaking

ii. Lucy squeaked to the police (only metaphorical) ${ }^{5}$

(9) OFs for the sound of boiling water:

a. Japanese:

i. Yu-ga bokoboko huttoo si-ta 'Water boiled burble-burble'

ii. Ana-ga bokoboko ai-te i-ru 'There are many large holes' (vestigial)

\footnotetext{
${ }^{5}$ Hideki Watanabe pointed out that the 'betray' meaning of squeak in (8d-ii) is attributed to the more general cultural image of canaries as betrayers. This type of information can be covered by an encyclopedic framework of semantics (see Section 5).
} 
b. Korean:

i. Mwul-i pwukulpwukul kkulh-nun 'Water is boiling burble-burble'

ii. Junho-ka pwukulpwukul kkulh-nun 'Junho is worrying himself' (only metaphorical)

c. Chinese:

i. Reshui gugu feiteng 'The hot water boiled burble-burble'

ii. $\phi$

d. English:

i. The water is burbling

ii. Joe was burbling on about the scandal (only metaphorical)

Third, many OFs in English (83.33\%) were found to have multiple meanings, especially in their colloquial or slang uses, in comparison with OFs in the other three languages $(25.00 \%)$ (Fisher's exact test: $p<.001)$. The following examples, as well as (7) through (9), illustrate this point.

(10) OFs for the noise of a saw:

a. Japanese:

i. Yui-ga ki-o kikokiko kit-ta 'Yui cut the tree squeak-squeak'

ii. $\phi$

b. Korean:

i. Minseo-ka namu-lul ssukssakssukssak cal-ess-ta

'Minseo cut the tree squeak-squeak'

ii. $\phi$

c. Chinese:

i. Wei cilacila ju zhe shu 'Wei was sawing the tree rasp-rasp'

ii. $\phi$

d. English:

i. The saw rasped and squeaked

ii. The noise rasped on their nerves (factive-metonymical)

In addition to these three characteristic tendencies, we obtained skewed distributions for the types of semantic extension. Our data consisted of fifty-six extended meanings, whose extension types are summarized in Table 3.

Table 3. Types of semantic extension of OFs in the four languages

\begin{tabular}{c|ccccc}
\hline & Only metaphorical & Factive-metonymical & Prospective & Vestigial & Total \\
\hline Japanese & 2 & 5 & 2 & 7 & 16 \\
Korean & 9 & 1 & 0 & 4 & 14 \\
Chinese & 1 & 1 & 0 & 0 & 2 \\
English & 16 & 4 & 1 & 3 & 24 \\
\hline Total & 28 & 11 & 3 & 14 & 56 \\
\hline
\end{tabular}

The limited size of the present data does not allow us to make a statistical argument. However, the relative richness of metonymical instances, both factive and fictive, in Japanese and that of (only) metaphorical instances in English are worth noting. For example, the 'having many large holes' meaning of the Japanese OF bokoboko in (9a) can be attributed to our vestigial understanding of the holes that were made with a burbling sound. On the other hand, the manner-of-speech meaning of English burble in (9d) is the 
PJOS 5(1), 2013

consequence of a metaphorical mapping from a boiling sound to a human voice. In the next section, we argue that the three constraints that underlie the present results for the semantic extensibility of OFs also capture those for their extension types.

\section{Three constraints and their origins}

The previous section pointed out three distributional characteristics of polysemous OFs in the four languages. In this section, we interpret them in terms of three general constraints each of which has independent grounds. It is proposed that the semantic extensibility of OFs is correlated with their referential specificity (Section 5.1), their event-structural complexity (Section 5.2), and their syntactic coreness (Section 5.3).

\subsection{Referential constraint}

The distinctly low semantic extensibility of Chinese OFs can be ascribed to their low referential specificity, which we already noted in Section 2.2. It appears that Chinese OFs are generally unspecified as to sound sources and perhaps sensitive to sound qualities. To reinforce the previous observations (Takeda, 2001; Yu, 2012b), we examined whether our OFs in the four languages can be applied to sounds made by more than one type of sound emitter.

The basic methods of examination were the same as described in Section 3. We asked native speakers of the four languages whether each OF is applicable to various types of sound sources. Their answers were analyzed by two linguists, and the concordance rate was $94.92 \%$ (112/118). The six divergent judgments were resolved by discussion. For example, one examiner judged kwangkwang in Korean as applicable to two types of sound-making events - "forceful contact" (e.g., stomping, knocking) and "explosion" (e.g., bombing) - which the other examiner lumped together as "strong impact." A brief discussion led them to decide on the latter.

Tables 4 and 5 present the results. OFs for multiple sound sources are followed by a check $(\checkmark)$, and those without are followed by an asterisk. 
Table 4. Referential neutrality of OFs in the four languages

\begin{tabular}{|c|c|c|c|c|c|c|c|c|c|}
\hline & & Japanese & & Korean & & Chinese & & English & \\
\hline Voice & 1 & doyadoya & $*$ & swullengswulleng & $*$ & $\mathrm{n} / \mathrm{a}$ & & hum & $\sqrt{ }$ \\
\hline \multirow[t]{7}{*}{ (+human) } & 2 & kerakera & $*$ & kkelkkel & $*$ & haha & $*$ & cackle & $\sqrt{ }$ \\
\hline & 3 & hisohiso & $*$ & ssoktokssoktok & $*$ & xisuo & $\checkmark$ & whisper & $\sqrt{ }$ \\
\hline & 4 & gebogebo & $*$ & uweyk & $*$ & wala & $*$ & barf & $*$ \\
\hline & 5 & gonyogonyo & $*$ & wumwulwumwul & $*$ & jiligulu & $\checkmark$ & mutter & $\checkmark$ \\
\hline & 6 & gyaagyaa & $*$ & kolaykolay & $*$ & $a a a$ & $*$ & scream & $\sqrt{ }$ \\
\hline & 7 & buriburi & $*$ & wakuwaku & $*$ & $\mathrm{n} / \mathrm{a}$ & & grumble & $\sqrt{ }$ \\
\hline & 8 & petyapetya & $\checkmark$ & caycalcaycal & $*$ & jijizhazha & $\checkmark$ & chatter & $\checkmark$ \\
\hline \multirow[t]{7}{*}{ (-human) } & 9 & wanwan & $\checkmark$ & mengmeng & $*$ & wangwang & $*$ & bowwow & $\sqrt{ }$ \\
\hline & 10 & hinhin & $*$ & hihing & $*$ & huierhuier & $*$ & neigh & $*$ \\
\hline & 11 & kaakaa & $*$ & kkakkkak & $*$ & yaya & $*$ & $c a w$ & $*$ \\
\hline & 12 & nyaanyaa & $*$ & yaongyaong & $*$ & miao & $*$ & meow & $*$ \\
\hline & 13 & tyuntyun & $*$ & ccaykccayk & $\sqrt{ }$ & jijizhazha & $\checkmark$ & chirp & $\checkmark$ \\
\hline & 14 & tyuutyuu & $\checkmark$ & ccikccik & $*$ & $j i j i$ & $*$ & squeak & $\sqrt{ }$ \\
\hline & 15 & gaagaa & $\checkmark$ & kkwaykkkwayk & $\checkmark$ & gaga & $\checkmark$ & quack & $\checkmark$ \\
\hline \multirow[t]{15}{*}{ Noise } & 16 & beriberi & $*$ & ccwakccwak & $*$ & cila & $*$ & rip & $*$ \\
\hline & 17 & dobodobo & $*$ & chempengchempeng & $*$ & putong & $\checkmark$ & gurgle & $\sqrt{ }$ \\
\hline & 18 & gatyagatya & $*$ & talkataktalkatak & $\checkmark$ & pa & $\checkmark$ & clatter & $\checkmark$ \\
\hline & 19 & kikokiko & $*$ & ssukssakssukssak & $\checkmark$ & cilacila & $*$ & rasp & $\sqrt{ }$ \\
\hline & 20 & potapota & $*$ & ttokttok & $\checkmark$ & dida & $\checkmark$ & trickle & $*$ \\
\hline & 21 & tyarityari & $*$ & cayngkulangcayngkulang & $*$ & dingdang & $\checkmark$ & jingle & $\sqrt{ }$ \\
\hline & 22 & dokadoka & $*$ & kwangkwang & $*$ & papapapa & $*$ & tramp & $*$ \\
\hline & 23 & bokoboko & $*$ & pwukulpwukul & $\checkmark$ & gugu & $\checkmark$ & burble & $\checkmark$ \\
\hline & 24 & zyakazyaka & $*$ & khwungkhwung & $\checkmark$ & dongdong & $\checkmark$ & blare & $\checkmark$ \\
\hline & 25 & potyapotya & $*$ & calpatang & $*$ & pia & $\checkmark$ & splash & $*$ \\
\hline & 26 & taputapu & $*$ & chollong & $*$ & gudonggudong & $\checkmark$ & plop & $\sqrt{ }$ \\
\hline & 27 & karikari & $*$ & atutukatutuk & $\checkmark$ & kuchikuchi & $*$ & crisp & $\checkmark$ \\
\hline & 28 & zakuzaku & $*$ & songsong & $*$ & $c a$ & $\checkmark$ & crunch & $\checkmark$ \\
\hline & 29 & baribari & $*$ & ccyangkulang & * & piaca & $\checkmark$ & crack & $\checkmark$ \\
\hline & 30 & gorogoro & $\checkmark$ & twululu & $\checkmark$ & gulugulu & $\checkmark$ & growl & $\checkmark$ \\
\hline
\end{tabular}

Table 5. Referentially neutral OFs in the four languages

\begin{tabular}{c|ccc}
\hline & Voice & Noise & Total \\
\hline Japanese & $4 / 15(26.67 \%)$ & $1 / 15(6.67 \%)$ & $5 / 30(16.67 \%)$ \\
Korean & $2 / 15(13.33 \%)$ & $7 / 15(46.67 \%)$ & $9 / 30(30.00 \%)$ \\
Chinese & $5 / 13(38.46 \%)$ & $11 / 15(73.33 \%)$ & $16 / 28(57.14 \%)$ \\
English & $11 / 15(73.33 \%)$ & $11 / 15(73.33 \%)$ & $22 / 30(73.33 \%)$ \\
\hline Total & $22 / 58(37.93 \%)$ & $30 / 60(50.00 \%)$ & $52 / 118(44.07 \%)$ \\
\hline
\end{tabular}

The results suggest that not only Chinese but also English OFs have high referential neutrality (or low referential specificity). For example, the Chinese OF for a human mutter jiligulu can also imitate the growling sound of the stomach. English mutter can also be used for the sound of a thunder and a wave. These flexible uses are not available for Japanese gonyogonyo and Korean wumwulwumwul. ${ }^{6}$ Likewise, Chinese dingdang mimics not only metals, such as coins and keys, but also electronics, such as doorbells. English jingle is also not limited to metallic sounds; it can also refer to pleasant rhymes and music. In contrast, the objects referred to by Japanese tyarityari and Korean

\footnotetext{
${ }^{6}$ It appears that animacy (i.e., the voice-noise distinction; see Section 5.2) is not a relevant factor in the range of coverage of Chinese and English OFs, as exemplified by jiligulu and mutter, which imitate the sounds of both animate and inanimate beings. Meanwhile, the present investigation found no single instance of such "cross-animacy" application for Korean OFs, which are restricted to sounds made by either animate or inanimate beings. The Japanese list contains two forms that are applied to both voice and noise: petyapetya (chatter and the sound of something mushy) and tyuutyuu (a mouse's squeak and the sound of a kiss).
} 
PJOS 5(1), 2013

cayngkulangcayngkulang are always metallic. The rate of referentially neutral items in Chinese was significantly higher than that of Japanese plus Korean (Fisher's exact test: $p$ $<.01)^{7}$

From a frame-semantic point of view, the low semantic extensibility of Chinese OFs can be attributed to the absence of specific frame elements, such as particular event participants and manners, in the frames they evoke. Their presence is likely to be a necessary condition for semantic extension, particularly metonymical extension, which is a focus shift between frame elements. Then, what makes referentially unspecified OFs in English so extensible? We answer this question by positing a syntactic constraint on the semantic extension of OFs in Section 5.3.

\subsection{Event-structural constraint}

The resistance of OFs for voice to semantic extension observed for Japanese and Korean in Section 4 is also ascribable to their frame semantics: the event-structural simplicity of voice OFs prevents them from flexible semantic shifts. Sound-symbolic lexemes are generally characterized by their highly specific frames (Akita, 2012). As Yu (2012a) points out for Japanese, however, OFs for voice and noise in the two languages are thought to evoke different types of frames.

On the one hand, a typical voice frame is assumed quite simple, consisting of the following set of frame elements.

(11) A voice frame:

a. The vocal sound (e.g., a scream)

b. An animate entity that produces it (e.g., a human being) ${ }^{8}$

c. Perhaps an emotional or non-emotional stimulus that causes the animate entity to make the sound (e.g., surprise, fear) (see Hasada, 2001; Feist, 2013)

On the other hand, a noise frame is highly complex, containing a causing subevent (or "subframe") (cf. Levin \& Rappaport Hovav, 1995; Levin, Song, \& Atkins, 1997).

A noise frame:

a. The sound

b. A subevent that causes or involves the sound $(\rightarrow(13),(14))$

This "subevent" is either an impact event or a change-of-state event. An impact event consists of the following elements, and this is a type of event to which a prospective expression, such as katikati 'frozen solid' in (4b) above, refers.

An impact event:

a. An impactor (e.g., a human being)

b. An impactee (e.g., a block of ice)

c. The state of the impactee (e.g., frozen solid)

\footnotetext{
${ }^{7}$ Noise OFs showed slightly greater referential neutrality than voice OFs when we excluded the English data (Fisher's exact test: $p<.10)$. This result is consistent with Yu's (2012a) observation that OFs for voice are generally tightly coupled with particular animate beings, especially animals (e.g., dogs for bowwow).

${ }^{8}$ Animal mimicry often takes irregular forms across languages (e.g., cock-a-doodle-doo). This fact suggests the relevance of the feature [ \pm human], as well as [ \pm animate], to the study of OFs. In fact, the present data include no single polysemous item for an animal cry.
} 
d. A particular manner of impacting (e.g., hitting)

e. An instrument (e.g., a stick)

In contrast, a change-of-state event consists of the following pieces of information. Vestigial expressions, such as barabara 'scattered' in (3b), refer to this type of event.
An change-of-state event:
a. A causer (e.g., a human being)
b. A particular means of causation (e.g., breaking)
c. An object (e.g., a branch)
d. Its initial state (e.g., not broken)
e. Its resultant state (e.g., broken)

As metonymical extension takes place between frame elements, it is quite natural that noise OFs metonymically shift their referents from sound to these various fragments of the frames they evoke. Conversely, the simple frame-semantic content of voice OFs does not allow them to have the semantic flexibility. ${ }^{9}$

\subsection{Syntactic constraint}

The semantic extensibility of OFs also depends on how they are realized syntactically. As we saw in Section 1, OFs are mostly realized as adverbs in Japanese, Korean, and Chinese, but as verbs in English. It follows that, while most OFs in English occur in the core of a clause, those in the former languages do not. In this section, we argue that the core of a clause is generally associated with higher semantic extensibility than its periphery, notably adjuncts. Evidence comes from the morphosyntactic variation in Japanese OFs and its semantic correlates, and the argument-adjunct asymmetry in semantic extension discussed in the literature.

First, reduplicative OFs in Japanese have two morphosyntactic options. One is a "quoted" form that is marked by the quotative particle -to, and the other is a bare form that is directly followed by its typical host. In a few cases, the presence and absence of the quotative particle causes a semantic difference in OFs (Akita \& Usuki, 2013). For example, the particle is optional when the OF gatagata is used in its basic meaning (i.e., the mimicry of a rattling noise), as in (15a), but it is unlikely to occur when the same form metaphorically mimics the grumbling manner of complaining, as in $(15 \mathrm{~b}){ }^{10}$

$$
\begin{aligned}
& \text { a. Amado-ga gatagata(-to) it-te i-ta } \\
& \text { sliding.shutter-NOM OF-QUOT say-CONJ be-PST }
\end{aligned}
$$

\footnotetext{
${ }^{9}$ The frame-semantic contrast between voice and noise OFs is indirectly reinforced by their morphological contrast in Japanese. Japanese sound-symbolic stems are based on either monomoraic $((\mathrm{C}) \mathrm{V})$ or bimoraic $\left((\mathrm{C})_{1} \mathrm{~V}_{1} \mathrm{C}_{2} \mathrm{~V}_{2}\right)$ roots. The latter are said to have more fine-grained phonosemantic values (Hamano, 1998) Our semantic classification of the 586 OFs in Kakehi, Tamori, \& Schourup (1996) revealed that $40.80 \%$ (51/125) of voice OFs and 85.90\% (396/461) of noise OFs have bimoraic roots. This suggests the soundsymbolic complexity of noise OFs, which is consistent with their frame-semantic complexity discussed here.

${ }^{10}$ Kiyoko Toratani independently, and prior to Akita \& Usuki, recognized this phenomenon. Moreover, Yo Matsumoto pointed out similar semantic contrasts in English verbs, citing a pair of sentences like (i), which were originally created by Dan Slobin. The verb stride in (ia) carries a psychological meaning like the one expressed by swagger, which is absent in its nominal use in (ib). See also the discussion of the argumentadjunct asymmetry in metonymical extension below.
}

(i) a. Max strode through the crowd

b. Max walked through the crowd with a stride 
PJOS 5(1), 2013

$$
\begin{aligned}
& \text { 'The sliding shutter was rattling' } \\
& \text { b. Amano-ga gatagata(??-to) it-te i-ta } \\
& \text { Amano-NOM OF-QUOT say-CONJ be-PST } \\
& \text { 'Amano was grumbling' }
\end{aligned}
$$

The quoted construction is an adjunct that often occurs separate from its host predicate, whereas the bare form is both syntactically and semantically strongly paired with the predicate (Toratani, 2006; Akita \& Usuki, 2013). Hence, the data suggests the correlation between the morphosyntactic integration and semantic extensibility of OFs (Dingemanse, 2011: Chapter 6 for a related discussion).

Next, the recent literature on cognitive semantics makes a related observation. Mostly on the basis of his English examples, Okada (2013: 164) argues that "[a]rguments lexically selected by the predicate of a sentence are more likely to become the target of conceptual expansion [ $\fallingdotseq$ metonymical extension] than adjunct elements" (cf. Waltereit, 1999). For example, the kettle and the door can metonymically refer to objects contiguous to their original referents when they appear as verbal arguments, as illustrated in (16a) and (17a). However, the same is unlikely to hold for these noun phrases occurring in adjunct positions, as illustrated in (16b) and (17b).

(16) a. The kettle is boiling (the kettle = water in the kettle)

b. ??I put out the fire with the kettle (??the kettle $=$ water in the kettle)

(Okada, 2013: 163-164)

(17) a. John answered the door

(the door $=$ the person on the other side)

b. ??John answered "Yes" in response to the door (??the door $=$ the person on the other side)

(Okada, 2013: 164)

These contrasts directly illustrate the correlation between syntax and semantic extensibility. Okada (2013: 164) employs a cognitive account for the argument-adjunct asymmetry, assuming that "[a]rguments are salient entities in a clause" that attract many processing efforts and are a suitable locus for costly elements that involve indirect formmeaning relationships. Although Okada's account is intended to capture the argumentadjunct asymmetry in metonymical extension, given its cognitive nature, it appears to be potentially applicable to similar phenomena concerning metaphorical and other types of semantic extension as well. Moreover, the idea is at least compatible with the core vs. periphery (i.e., predicate/bare vs. non-predicate/quoted) asymmetries in semantic extensibility observed above. Grammatically core positions are more suitable for semantically extended items, which involve indirect form-meaning relationships, than peripheral positions.

The priority of predicates, more precisely verbs, in semantic extension may also have a semantic motivation. Verbs denote processes (Langacker, 1990; Croft, 1991). It appears to be this semantic property that allows even referentially unspecified OFs in English to have multiple meanings. In fact, the major type of semantic extension in English OFs is not metonymy but (only) metaphor (Section 4), which yields a notable number of manner-of-speech verbs (Zwicky, 1971; Inoue, 2010). Interestingly, this extension path is 
shared by the Japanese bare (quasi-predicative) OF in (15b) above. It appears that metaphor, a domain-to-domain mapping, does not require fine-grained frame elements, and is even applicable to mere combinations of the sounds imitated by OFs and the process feature of the verb.

Thus, the core of a clause is generally a more appropriate position for semantic extension than its periphery. Given the high semantic extensibility of English OFs, both voice and noise, this morphosyntax-semantics correlation overrides both the referential constraint in Section 5.1 and the event-structural constraint in Section 5.2.

\section{Conclusion}

In this article, we have argued that the polysemy patterns of OFs are formed by three well-motivated constraints concerning their referential specificity, event-structural complexity, and syntactic status. The discussion is summarized in Figure 2.

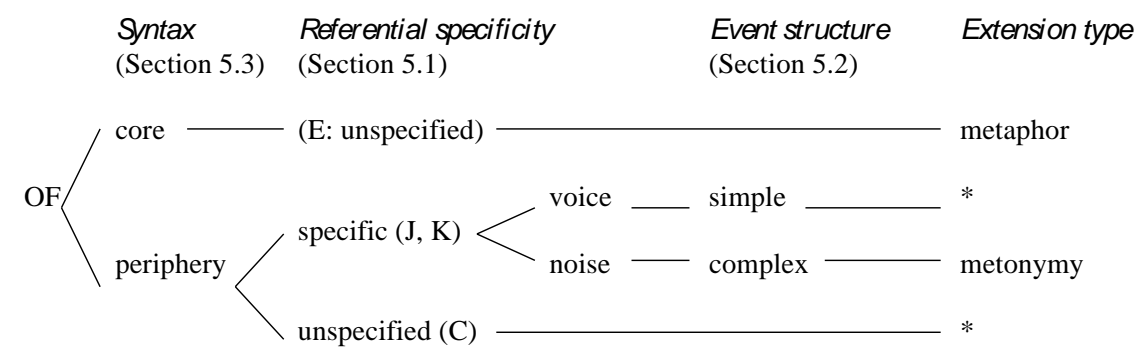

Figure 2. Summary

The strongest factor is syntax, which distinguishes English from the other three languages. The "periphery" node subsumes Japanese and Korean, whose OFs have finegrained referentiality, and Chinese, whose OFs are referentially unspecified. In the former languages, voice OFs are more resistant to semantic extension than noise OFs. English OFs, which are referentially unspecified and mainly realized in the core of a clause, prefer metaphorical extension, whereas frame-semantically rich noise OFs in Japanese and Korean prefer metonymical extension. Thus, the present study puts forward and complements the frame-semantic approach to the polysemy of OFs, which has discussed existing, rather than non-existing, cases of semantic extension in each language. ${ }^{11}$

As the present study is based on a small set of data taken from only four languages, further examinations are needed to refine and modify those initial generalizations. In particular, languages with referentially specific onomatopoeic verbs, if any, will play an important role in our elaboration of the ranking among the three constraints. ${ }^{12}$ Future investigations will also have to answer where the crosslinguistic difference in the referential specificity of OFs comes from. We hope that the present study will work as a starting point for such typological investigations and lead to a fundamental contribution to the current cognitive trends in sound symbolism research.

\footnotetext{
${ }^{11}$ An earlier version of this paper attempted to unify the three constraints as a general constraint that prohibits "highly iconic" OFs from semantic extension (see Akita, 2013 for a related discussion). In this alternative (over)generalization, neutrality to sound sources (interpreted as sensitivity to sound qualities), vocal mimicry of vocal sounds (i.e., voice $\mathrm{OFs}$ ), and syntactic periphery (especially quotative constructions) were all linked to high iconicity. At least some parts of the proposal might still be worth consideration.

${ }^{12}$ This goal may also be achieved statistically - by means of a logistic regression model, for example.
} 
PJOS 5(1), 2013

\section{Acknowledgements}

An earlier version of this article was presented at the 7th International Conference on Cognitive Science in 2010. I benefited from discussions with Masako Hiraga, Iksoo Kwon, Qi Li, Min-Jung Sun, Kohei Suzuki, Kiyoko Toratani, Takeshi Usuki, Wei-Lun $\mathrm{Yu}$, and people at IO-Lab and the Linguistic Department at Kobe University. I also thank Jordan Zlatev and an anonymous reviewer for their constructive comments. Remaining inadequacies are mine. This study was partly supported by Grant-in-Aid for Young Scientists (B) (no. 24720179), Grant-in-Aid for Scientific Research (C) (no. 25370425; PI: Masako Hiraga), and a grant from Spanish Ministry of Economy and Competitiveness (no. FFI2010-14903; PI: Iraide Ibarretxe-Antuñano).

\section{References}

Akita, K. (2012). Toward a frame-semantic definition of sound-symbolic words: A collocational analysis of Japanese mimetics. Cognitive Linguistics, 23, 67-90.

Akita, K. (2013). The lexical iconicity hierarchy and its grammatical correlates. In L. Elleström, O. Fischer, and C. Ljungberg (Eds.), Iconic investigations (pp. 331-349). Amsterdam/Philadelphia: John Benjamins.

Akita, K., \& Usuki, T. (2013). A constructional account of mimetic quasi-incorporation in Japanese. Ms., Osaka University \& Fukuoka University.

Aoyama, H. (1991). Tyoosengo syootyoogo-ziten [A dictionary of Korean soundsymbolic words]. Tokyo: Daigaku Shorin.

Croft, W. (1991). Syntactic categories and grammatical relations: The cognitive organization of information. Chicago: University of Chicago Press.

Croft, W. (1993). The role of domains in the interpretation of metaphors and metonymies. Cognitive Linguistics, 4, 335-370.

Dingmanse, M. (2011). The meaning and use of ideophones in Siwu. Ph.D. dissertation, Max Planck Institute for Psycholinguistics, Nijmegen/Radboud University.

Feist, J. (2013). "Sound symbolism" in English. Journal of Pragmatics, 45, 104-118.

Fillmore, C. J., \& Baker, C. (2010). A frames approach to semantic analysis. In B. Heine and H. Narrog (Eds.), The Oxford handbook of linguistic analysis (pp. 313-340). Oxford: Oxford University Press.

Hamano, S. (1998). The sound-symbolic system of Japanese. Tokyo: Kurosio Publishers.

Hasada, R. (2001). Meanings of Japanese sound-symbolic emotion words. In J. Harkins and A. Wierzbicka (Eds.), Emotions in crosslinguistic perspective (pp. 217-253). Berlin/New York: Mouton de Gruyter.

Hinton, L., Nichols, J., \& Ohala, J. J. (Eds.) (1994). Sound symbolism. Cambridge: Cambridge University Press.

Ibarretxe-Antuñano, I. (2006). Sound symbolism and motion in Basque. München: LINCOM Europa.

Imai, M., Kita, S., Nagumo, M., \& Okada, H. (2008). Sound symbolism facilitates early verb learning. Cognition, 109, 54-65.

Inoue, K. (2010). Rhetoric of onomatopoeia: Cognitive linguistic study on neologism of onomatopoeia and mimetics. Ph.D. dissertation, Osaka University.

Kageyama, Y. (2013). Hangariigo-onomatope-ni mirareru imi-kakutyoo [Semantic extension in Hungarian onomatopoeia]. M.A. thesis, Osaka University.

Kakehi, H., Tamori, I., \& Schourup, L. (1996). Dictionary of iconic expressions in Japanese. Berlin/New York: Mouton de Gruyter. 
Kita, S. (1997). Two-dimensional semantic analysis of Japanese mimetics. Linguistics, $35,379-415$.

Kloe, D. R. (1977). A dictionary of onomatopoeic sounds, tones and noises in English and Spanish including those of animals, man, nature, machinery and musical instruments, together with some that are not imitative or echoic. Detroit, MI: Blaine Ethridge.

Kunihiro, T. (1985). Ninti-to gengo-hyoogen [Cognition and linguistic expressions]. Gengo Kenkyuu, 88, 1-19.

Lakoff, G. (1987). Women, fire, and dangerous things: What categories reveal about the mind. Chicago: University of Chicago Press.

Lakoff, G., \& Johnson, M. (1980). Metaphors we live by. Chicago: University of Chicago Press.

Lakoff, G., \& Johnson, M. (1999). Philosophy in the flesh: The embodied mind and its challenge to Western thought. New York: Basic Books.

Langacker, R. W. (1990). Concept, image, and symbol: The cognitive basis of grammar. Berlin/New York: Mouton de Gruyter.

Levin, B. (1993). English verb classes and alternations: A preliminary investigation. Chicago: University of Chicago Press.

Levin, B., \& Rappaport Hovav, M. (1995). Unaccusativity: At the syntax-lexical semantics interface. Cambridge, MA: MIT Press.

Levin, B., Song, G., \& Atkins, B. T. S. (1997). Making sense of corpus data: A case study of verbs of sound. International Journal of Corpus Linguistics, 2, 23-64.

Lu, C. (2006). Giongo/gitaigo-no hiyu-teki-kakutyoo-no syosoo: Ninti-gengogaku-to ruikeiron-no kanten-kara [Aspects of figurative extensions of mimetics: From cognitive linguistic and typological perspectives]. Ph.D. dissertation, Kyoto University.

Maurer, D., Pathman, T., \& Mondloch, C. J. (2006). The shape of boubas: Sound-shape correspondences in toddlers and adults. Developmental Science, 9, 316-322.

Meng, C. (2012). A description of ideophonic words in Mandarin Chinese. M.A. thesis, Leiden University.

Mikami, K. (2006). Nihongo-no giongo/gitaigo-ni okeru imi-no kakutyoo: Konseki-tekininti/yoki-teki-ninti-no kanten-kara [Semantic extension in Japanese mimetics: From the perspective of vestigial and prospective cognition]. Studies on Japanese Language and Literature, 57, 199-217.

Nakamoto, K., Kotani, K., \& Isahara, H. (2004). Yoki-teki-ninti-to keiyoo-hyoogen: Huan-ni motozuku zyookyoo-haaku [Prospective cognition and interpretation of adjectives]. Proceedings of the 4th Annual Meeting of the Japanese Cognitive Linguistics Association (pp. 34-44).

Noguchi, M. (1995). Tyuugokugo giongo-ziten [A dictionary of Chinese onomatopoeic words]. Tokyo: Toho Shoten.

Nuckolls, J. B. (2010). The sound-symbolic expressions of animacy in Amazonian Ecuador. Diversity, 2, 353-369.

Nygaard, L. C., Cook, A. E., \& Namy, L. L. (2009). Sound to meaning correspondences facilitate word learning. Cognition, 112, 181-186.

Okada, S. (2013). (Ir)regularity of conceptual expansions in adjunct nominals. In S. Okada (Ed.), Osaka University Papers in English Linguistics, 16, 161-185.

Sohn, H. (1994). Korean. London: Routledge.

Takeda, M. (2001). Tyuugokugo-ni miru kyookankaku-hiyu-ni tuite-no iti-koosatu: Giongo-no gitaigoka-o megutte [A study of synesthetic metaphor in Chinese: On the 
PJOS 5(1), 2013

shift from onomatopoeic to non-onomatopoeic mimetics]. Language Sciences, 14, 107-118. Nagoya University.

Talmy, L. (1985). Lexicalization patterns: Semantic structure in lexical forms. In T. Shopen (Ed.), Language typology and syntactic description, Vol. 3: Grammatical categories and the lexicon (pp. 57-149). Cambridge: Cambridge University Press.

Talmy, L. (1996). Fictive motion in language and 'ception'. In P. Bloom, M. A. Peterson, L. Nadel, and M. F. Garrett (Eds.), Language and space (pp. 211-276). Cambridge, MA: MIT Press.

Toratani, K. (2006). On the optionality of to-marking on reduplicated mimetics in Japanese. In T. J. Vance \& K. Jones (Eds.), Japanese/Korean linguistics, 14 (pp. 415422). Stanford: CSLI Publications.

Voeltz, F. K. E., \& Kilian-Hatz, C. (Eds.) (2001). Ideophones. Amsterdam/Philadelphia: John Benjamins.

Waltereit, R. (1999). Grammatical constraints in metonymy: On the role of the direct object. In K. U. Panther and G. Radden (Eds.), Metonymy in language and thought (pp. 233-253). Amsterdam/Philadelphia: John Benjamins.

$\mathrm{Yu}$, W. (2012a). Hureemu-no kanten-kara miru nihongo-no giongo: Imi-to imi-kakutyooo tyuusin-ni [Japanese onomatopoeic words in terms of frames: Focusing on their meanings and semantic extension]. Proceedings of the 2012 International Conference on Japanese Language Education (pp. 237-251). Taipei: Soochow University.

Yu, W. (2012b). Nit/tyuu-ryoo-gengo-ni okeru giongo-no koosatu: Imi-kakutyoo-kara mi-ta tokusei-o megut-te [A research on onomatopoeic words in Japanese and Chinese: Based on the feature of semantic extension]. Proceedings of the 12th Annual Meeting of the Japanese Cognitive Linguistics Association (pp. 140-152).

Zwicky, A. M. (1971). In a manner of speaking. Linguistic Inquiry, 2, 223-233. 